\title{
Bias Correction of MRI-WRF Dynamic Downscaling Datasets
}

\author{
Yuan-Fong Su, ${ }^{1, *}$, Chao-Tzuen Cheng ${ }^{1}$, Jun-Jih Liou ${ }^{1}$, Yung-Ming Chen ${ }^{1}$, and Akio Kitoh ${ }^{2}$ \\ ${ }^{1}$ National Science and Technology Center for Disaster Reduction, New Taipei City, Taiwan, R.O.C. \\ ${ }^{2}$ Life and Environmental Sciences, University of Tsukuba, Tsukuba, Japan
}

Received 19 May 2015, revised 19 July 2016, accepted 14 July 2016

\begin{abstract}
The dynamic downscaling dataset provides useful insight for future climate change at the local scale. The original downscaled dataset, however, inevitably involves bias and hampers its further applications. This study presents a bias correction method that uses the quantile mapping method to a dynamic downscaled dataset originated from the Meteorological Research Institute (MRI). Daily solar radiation and hourly typhoon rainfall are selected as target variables to be corrected because they are critical variables in hydrological and agricultural practice. The results reveal that the original biases in the two datasets were markedly reduced and the statistical characteristics in the projections were much closer to that in the observations. After correction, the future changes in daily solar radiation and hourly typhoon rainfall are also evaluated. A decrease in solar radiation is suggested up to $\sim 5 \%$ in south and west parts of Taiwan in the late $21^{\text {st }}$ century while an increasing amount, about $2 \%$, will occur in the mountain areas. A significant increase in typhoon rainfall amount, up to $250 \%$ is observed in the west and central parts of Taiwan in the late $21^{\text {st }}$ century and $\sim 20 \%$ in the early $21^{\text {st }}$ century $(2015-2039)$. A decrease in typhoon rainfall amount, up to $\sim-30 \%$, is clear for the north and east parts of Taiwan.
\end{abstract}

Key words: Bias correction, Dynamic downscaling dataset, Daily solar radiation, Hourly typhoon rainfall

Citation: Su, Y. F., C. T. Cheng, J. J. Liou, Y. M. Chen, and A. Kitoh, 2016: Bias correction of MRI-WRF dynamic downscaling datasets. Terr. Atmos. Ocean. Sci., 27, 649-657, doi: 10.3319/TAO.2016.07.14.01

\section{INTRODUCTION}

Extreme weather disasters such as flooding, landslides, and droughts have occurred frequently and widely in recent years in Taiwan. To better understand the impacts of these extreme events, quantitative assessment of the future changes in these extreme events is an important issue. As such, there is an increasing need for high-resolution climate models that simulate climate phenomena at the local scale. This kind of high-resolution climate model is able to simulate small-scale weather patterns, such as tropical cyclones, with a horizontal resolution of only a few kilometers (Mizuta et al. 2012). Promising data exists to assess long-term, (longer than several decades, changes of extreme weather events); however, these data are not free of problems. Various sources of uncertainties such as the model's compactness, parameters disturbances and initial/boundary condition bias in the high-resolution model output are unavoidable (Christensen et al. 2008; Rojas et al. 2011).

\footnotetext{
* Corresponding author

E-mail:yaunfongsu@ncdr.nat.gov.tw
}

The bias in models must be corrected before application to further practices in order to produce reliable impact assessments. A number of approaches have been suggested for statistical bias correction (Wood et al. 2004; Elshamy et al. 2009) and dynamic (Mao et al. 2015) downscaling datasets. Most of these approaches aimed to adjust the model outputs as close to the observations as possible in terms of statistical characteristics such as the mean and standard deviation (SD). Some attempts focused on adjusting the statistical characteristics of global climate model (GCM) outputs in monthly, seasonal, or annual timescales (Johnson and Sharma 2011; Haerter et al. 2011) while others focused on regional climate model (RCM) output for daily timescale (Teutschbein and Seibert 2012) or monthly scale (Christensen et al. 2008). However, a bias correction to a dynamic downscaled RCM at the hourly scale is rarely discussed. The major aim of this study is to remove the bias in the dynamic downscaled RCM outputs for application to hourly typhoon rainfall and daily solar radiation data.

The reason that hourly typhoon rainfall and daily solar 
radiation are selected for bias correction is based on the research demands of a national major climate change project in Taiwan, the Taiwan Climate Change Projection and Information Platform (TCCIP) funded by the Ministry of Science and Technology, Taiwan. TCCIP aims to provide sound climate change datasets (statistical and dynamic downscaling) to end users in various fields such as hydrology and agriculture. Typhoon rainfall is the most important trigger for hydrological applications such as flooding simulations and landslides induced by heavy rainfall. For agricultural applications, daily solar radiation is the most significant climate factor in agricultural productions. Unfortunately, both hourly typhoon rainfall and daily solar radiation present biases in the raw RCM output data making a correction procedure necessary.

Bias correction can be conducted using parametric or nonparametric approaches with observed and projected datasets in the baseline (Teutschbein and Seibert 2012). The parametric approaches assume an identical statistical distribution and thus parameter estimation errors are inevitable. Furthermore, the distribution selected to fit the projected baseline dataset is not necessarily the same in the future. Therefore, a nonparametric approach is used in this study. Numerous nonparametric approaches have been proposed in literature such as linear scaling, variance scaling, quantile mapping etc. (Johnson and Sharma 2011; Haerter et al. 2011). However, linear scaling and variance scaling only adjust the mean and variance of the projection data and may fail to correct the bias presented in a skewed sample distribution (e.g., extreme rainfall). Quantile mapping aims to correct projection data toward identical population features (e.g., mean, variance, skewness etc.) with the observations and is used in this study.

The major aim of this study is to correct the biases of dynamic downscaled datasets, hourly typhoon rainfall and daily solar radiation, using the quantile mapping approach. The representability of the corrected datasets is also evaluated. After bias correction, possible future changes in daily solar radiation and hourly typhoon rainfall spatial patterns are also illustrated.

\section{MATERIALS AND METHOD}

\subsection{Materials}

Through cooperation between two major national climate change projects from Taiwan and Japan (TCCIP, http://tccip.ncdr.nat.gov.tw/NCDR/main/index.aspx; and KAKUSHIN Program, https://www.jamstec.go.jp/ kakushin21/eng/kakushin.html) the dynamic downscaled dataset, originated from the Meteorological Research Institute (MRI) of the Japan Meteorological Agency (JMA), named MRI-AGCM 3.2S, the S refers to super-high resolution, is used in this study. The Atmospheric General Circulation Model (AGCM), MRI-AGCM 3.2S with a $20-\mathrm{km}$ grid, is based on the JMA operational weather prediction model in which a quasi-conservation semi-Lagrangian dynamics is implemented. A radiation scheme and land surface scheme are developed. Present-day and future climate simulations are performed using the observed sea surface temperature (SST) and SST change projected by atmosphere-ocean coupled models as the lower boundary condition (Mizuta et al. 2012). The future climate simulation results provide a large amount of information including possible changes in tropical cyclones, the East Asian monsoon, extreme events, and blocking (Mizuta et al. 2006, 2012; Oouchi et al. 2006; Kitoh et al. 2008).

We further downscaled it into 5-km grid hourly data using the WRF 3.1.1 model (Weather Research and Forecasting modelling system) developed by National Center for Atmospheric Research (NCAR) with a 5-km terrain data to enhance the MRI-AGCM 3.2S resolution for local study in Taiwan. The modules consist of WRF Single-Moment 6-Class Microphysics scheme (WSM6), Noah land surface module, Monin-Obukhov surface layer scheme, Rapid Radiative Transfer Model (RRTM) for long-wave radiation, and Dudhia for short-wave radiation. Driven by the MRI data as the initial and boundary conditions, no nested-grid treatment and 5-km horizontal resolution cells, and 36 vertical layers are implemented in the WRF model. The simulation periods follow the MRI-AGCM 3.2S setting which is comprised of the late $20^{\text {th }}$ century, and also termed as the baseline, (1979 - 2003), the early $21^{\text {st }}$ century (2015 - 2039), and the late $21^{\text {st }}$ century $(2075-2099)$. This dataset is denoted by MRI-WRF hereafter.

Ground observations were collected from gauges around Taiwan for bias correction. There are 84 rainfall gauges with hourly records during 1979 - 2003 collected from the Water Resources Agency (WRA) and Central Weather Bureau (CWB) used in this study (Fig. 1). The focus of this study is on the rainfall during typhoon events, defined by the CWB with official records. Therefore, only the data from both datasets within the typhoon event period are used in the analysis.

The observed daily solar radiation datasets were collected from the CWB and Taiwan Agricultural Research Institute (TARI). There are 33 radiation gauges with record lengths of 15 years (Fig. 1). An inconsistency problem in the radiation data from the CWB occurred at the end of 2002 because the radiation instruments were calibrated at the end of 2002. This calibration results in time series before and after 2003 separated into different levels (Fig. 2a). The two mean value separation is statistically significant by $\mathrm{T}$ test at the $1 \%$ significant level. There is no such problem in the radiation dataset from TARI (Fig. 2b). Figure 2 shows that the MRI-WRF radiation was overestimated, therefore, there is a clear need for bias correction. Based on the fundamental of not to alter any observation and considering the consistency between datasets; we used only the observations after 2003 for the solar radiation bias correction. 


\subsection{Method}

Quantile mapping $(\mathrm{QM})$ is a nonparametric method that matches the full distribution of dataset between the projection and observation (Johnson and Sharma 2011). Assume that we have a projected dataset with sample size of $\mathrm{n}\left(X_{P, i}\right.$, $i=1,2, \ldots, \mathrm{n})$ and an observed dataset with sample size of $\mathrm{m}$ $\left(X_{O, i}, i=1,2, \ldots, \mathrm{m}\right)$. The empirical cumulative distribution functions $(E C D F)$ for the projected and observed datasets are calculated and denoted as $F_{p}$ and $F_{O}$, respectively. In the ECDF, each value (e.g., $X$ ) has a corresponding quantile $(q)$. For example, the $i^{\text {th }}$ projected value $\left(X_{P, i}\right)$ corresponds to $j^{\text {th }}$ quantile $\left(q_{P, j}\right)$ of $F_{P}$. Therefore, the bias-corrected value $\left(X_{C}\right)$ can be expressed as

$$
X_{C, i}=F_{O}^{-1}\left[q_{P, j}\left(X_{P, i}\right)\right]
$$

where $F_{O}^{-1}$ is the corresponding value of a given quantile in the ECDF of observations $\left(F_{O}\right)$. The process of QM is illustrated in Fig. 3. A correction factor $(R)$ could be denoted by the ratio of the projected values before and after $\mathrm{QM}$ :

$$
R\left(X_{P, i}\right)=\frac{X_{C, i}}{X_{P, i}}
$$

This ratio $(R)$ was applied to the projected dataset in the future under the assumption that the population features remain the same between the baseline and future periods. Therefore, the bias-corrected value can be rewritten as

$$
X_{C, i}^{t}=X_{P, i}^{t} \times R\left(X_{P, i}^{t}\right)
$$

where $X_{P, i}^{t}$ represents the $i^{\text {th }}$ projected value in $t$ period (the early $21^{\text {st }}$ century, the late $21^{\text {st }}$ century) and $X_{C, i}^{t}$ is its biascorrected value.

It is worth noting that the data used for bias correction in this study are at different time scales. The radiation data is in daily intervals while the rainfall data is in hourly intervals. The hourly rainfall data for typhoon events were selected to conduct bias correction. The reasons were (1) typhoon rainfall is the major cause of flooding and also the major water resource contribution; (2) there are many rainfall types in Taiwan, such as typhoons, Mei-Yu, convective storms etc., driven by various weather patterns. Using only typhoon rainfall from two datasets assures that the population features of two datasets are the same, which is also the aim of quantile mapping.

With projected and observed data during the baseline (1979 - 2003) the QM approach is applied here to correct biases in the future projections. The point data at gauges and the MRI-WRF grids encompassing the gauges are used for the correction based on the assumption that the projection in a MRI-WRF grid is uniform. This is a common assumption widely accepted by meteorologists and hydrologists.

After bias correction a comparison between projections in the future and based periods were conducted by calculating the change rate $(\mathrm{CR})$ defined as

$$
\mathrm{CR}(\%)=\frac{X_{\text {Future }}-X_{\text {Base period }}}{X_{\text {Base period }}} \times 100 \%
$$

where $X_{\text {Base period }}$ is the variable in the baseline and $X_{\text {Future }}$ is in the future (the early or late $21^{\text {st }}$ century).

\section{RESULTS}

\subsection{Hourly Typhoon Rainfall}

The hourly rainfall of the 84 gauges for 25 years
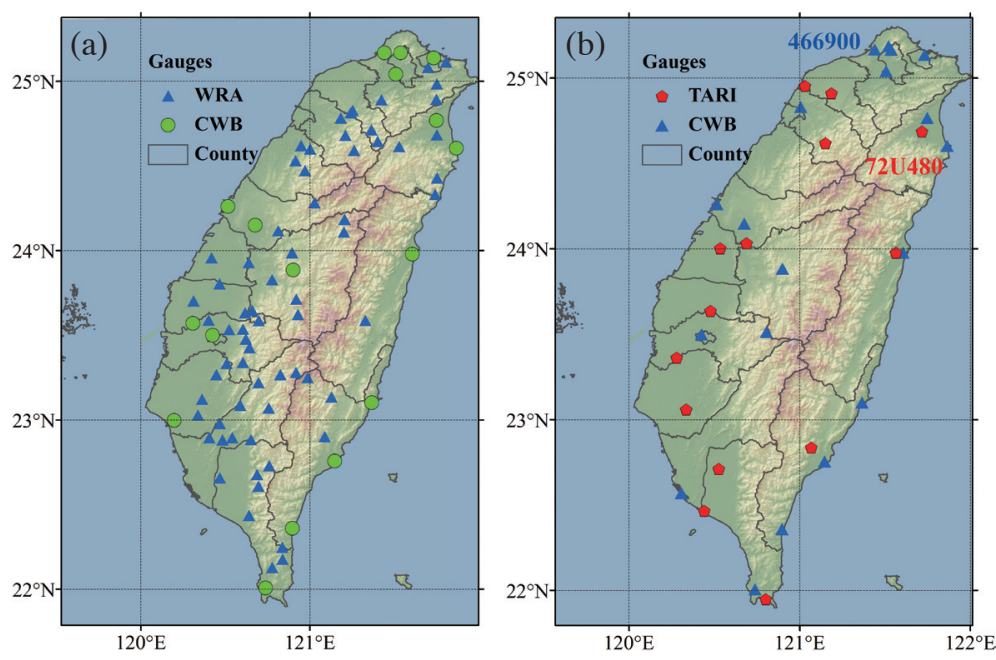

Fig. 1. Locations of ground measurements (a) rainfall gauges; (b) radiation gauges. 

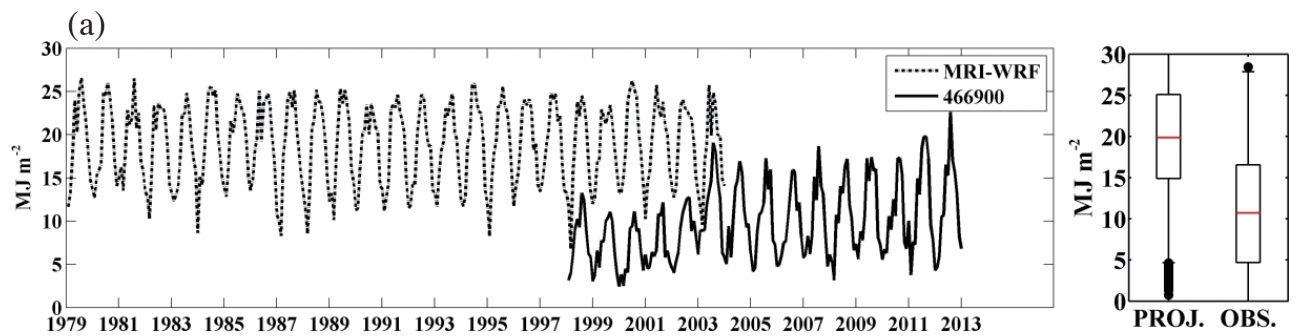

(b)
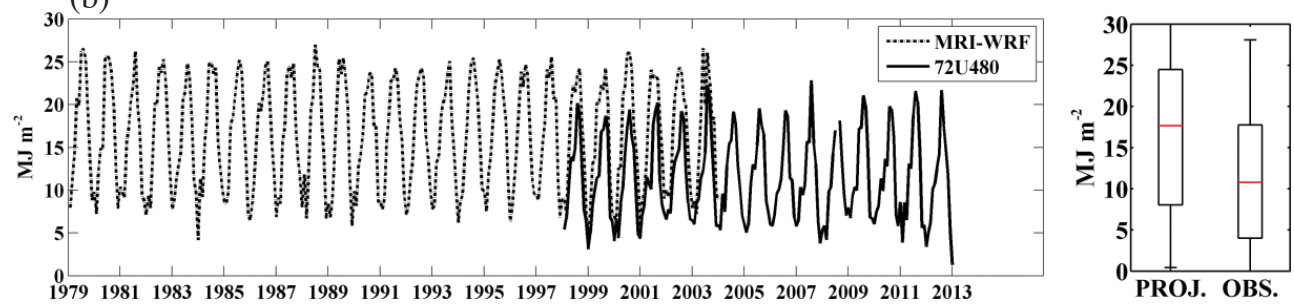

Fig. 2. Comparison between monthly averaged solar radiation of MRI-WRF and observations and the boxplots of daily solar radiation of different gauges (a) CWB ID: 466900; (b) TARI ID: 72U480. The locations of these two gauges are shown in Fig. 1.

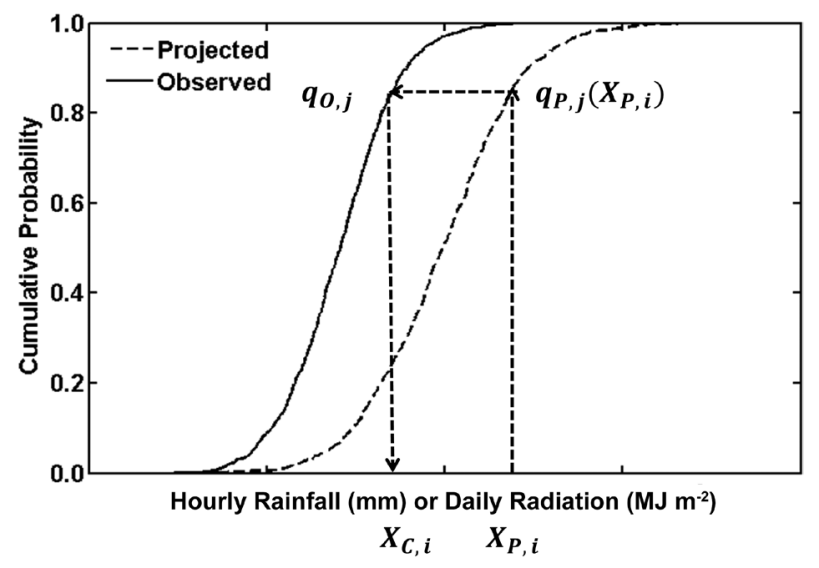

Fig. 3. Illustration of quantile mapping for bias correction.

together forms the ECDF of the observed dataset and corresponding data from the 84 MRI-WRF grids forms the ECDF of the projected dataset. Following the procedure illustrated in Fig. 3 the original projected MRI-WRF hourly typhoon rainfall was corrected using Eq. (1). The correction factors for hourly typhoon rainfall $\left(R_{T R}\right)$ are shown in Fig. 4 . The correction factors for hourly typhoon rainfall were all larger than 1 implying that the original MRI-WRF outputs were enlarged to reduce the underestimation problem. Notably, the $R_{T R}$ was a nonlinear function of the original projected hourly typhoon rainfall and it decreased to around 1.25 when the projected values were larger than $60 \mathrm{~mm} \mathrm{hr}^{-1}$. When comparing the total rainfall from typhoon events for the 84 gauges and the corresponding MRI-WRF grids, the scatter plots in Fig. 5 reveal that the scatter points are much closer to the equivalent line after bias correction; while the root mean square error (RMSE) also dropped from 643.5 to $419.4 \mathrm{~mm}$. The spatial distribution of the averaged typhoon rainfall amount derived from the projected data also agreed with the observed data, and a marked improvement in the underestimation could be found in Figs. $6 \mathrm{a}-\mathrm{c}$. These results strongly suggested that the bias correction was necessary and promising.

Applying the correction factor $\left(R_{T R}\right)$ to all 1566 projected grids, a generally increasing typhoon rainfall amount trend is observed from Figs. 6d - f, especially in the south and central part of Taiwan. The increasing future total typhoon event rainfall was quantified by the change rate (Fig. 7). It was apparent that the increasing trend is located mainly in the west and central parts of Taiwan, up to $\sim 50 \%$ in the late $21^{\text {st }}$ century, while a decreasing trend was also clear, up to $-30 \%$ in the late $21^{\text {st }}$ century, in the north and east parts of Taiwan.

\subsection{Daily Solar Radiation}

Two data series comprising all 33 gauges from TARI and CWB and the corresponding 33 MRI-WRF grids in the 
baseline were used for the QM approach. The correction factors for daily solar radiation $\left(R_{S R}\right)$ are shown in Fig. 8 . Notably, the ratio is not linearly increasing with the projected value before correction implying that the correction is a non-linear procedure. It was clear that all of the $R_{S R}$ values less than 1 , which indicated that the corrected solar radi-

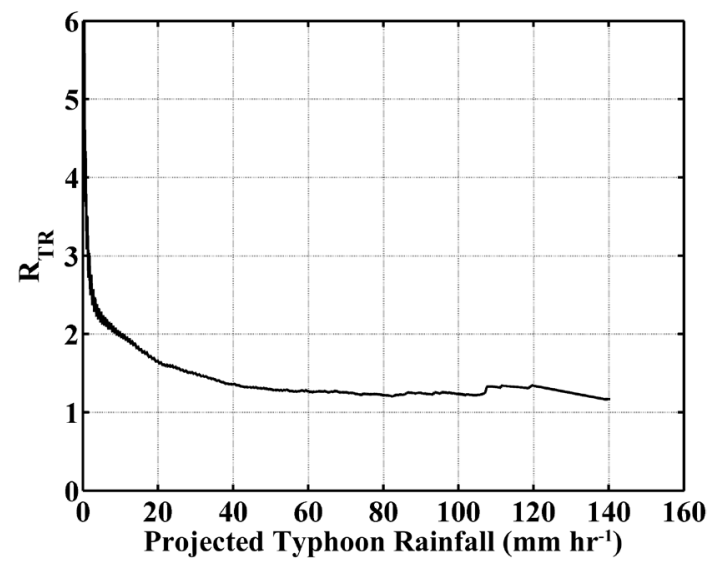

Fig. 4. Correction factor for hourly typhoon rainfall. ance will be smaller than the original value and therefore, will reduce the daily solar radiance overestimation problem in the original MRI-WRF outputs. Figure 9 shows that the monthly average time series for projected and observed solar radiance are much closer while it was also obvious from the boxplots that the daily solar radiation distributions

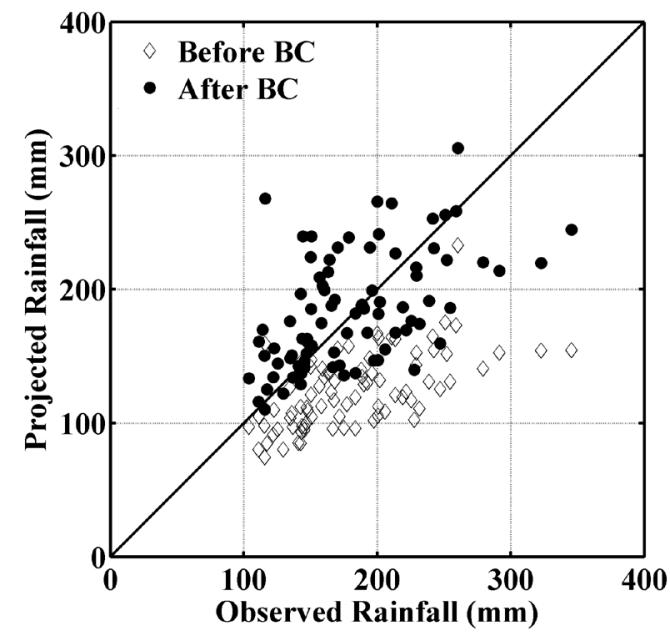

Fig. 5. Scatter plots of averaged typhoon rainfall amount before and after bias correction.
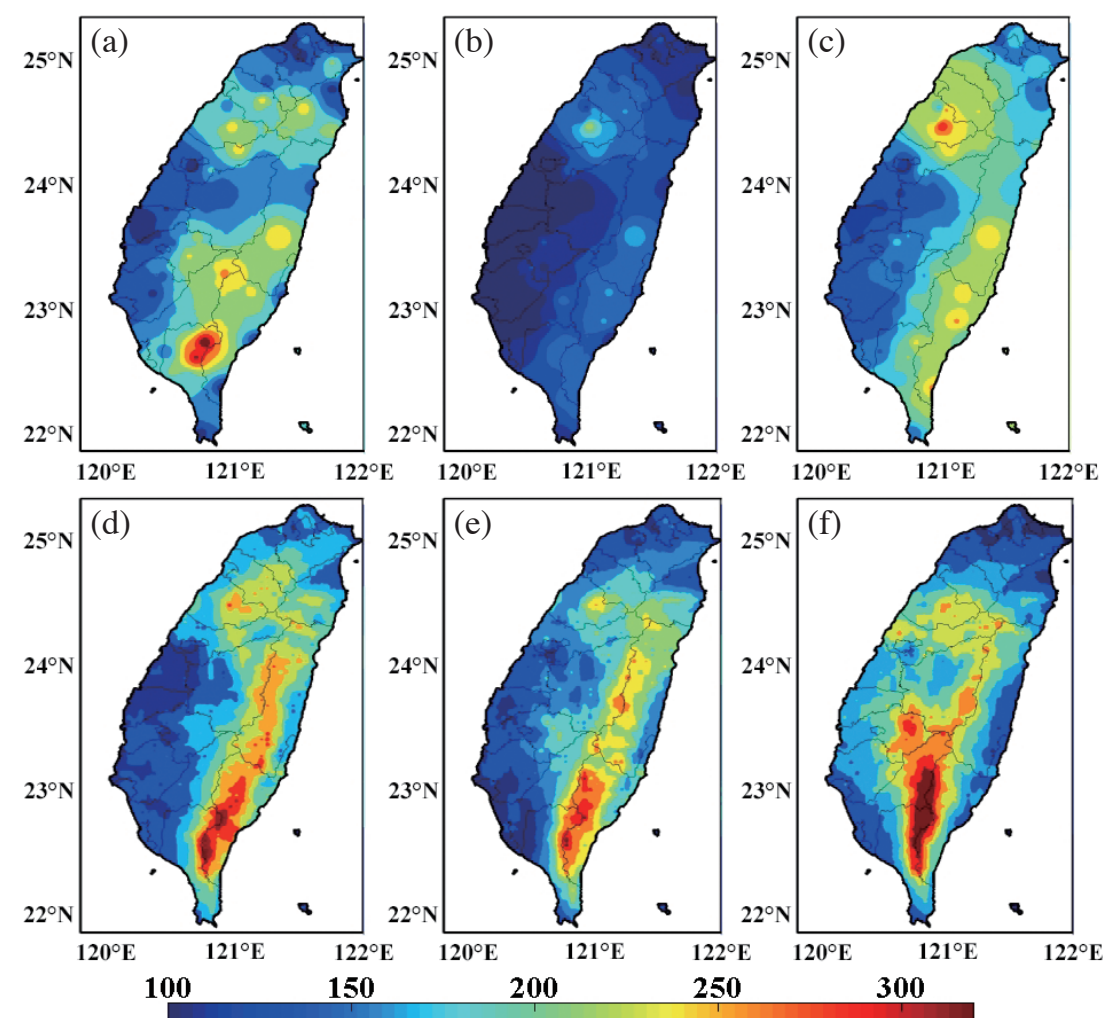

Fig. 6. Maps of averaged typhoon rainfall amount (mm) (a) 84 gauges and MRI-WRF; (b) 84 grids before correction; (c) 84 grids in the baseline after correction; (d) all grids in the baseline after correction; (e) all grids in the early $21^{\text {st }}$ century after correction; (f) all grids in the late $21^{\text {st }}$ century after correction. 


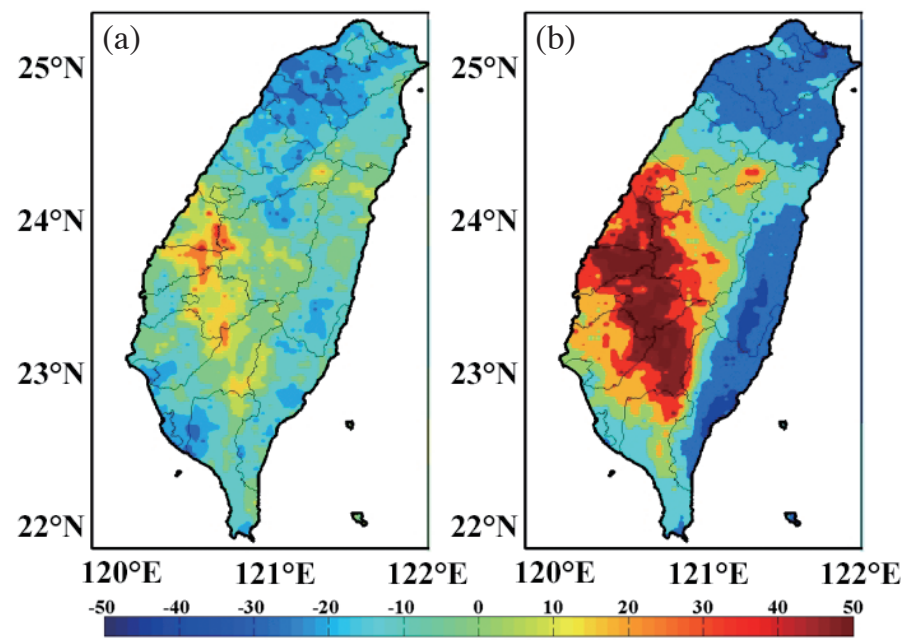

Fig. 7. Change rate (\%) of future projection typhoon rainfall (a) the early $21^{\text {st }}$ century; (b) the late $21^{\text {st }}$ century.

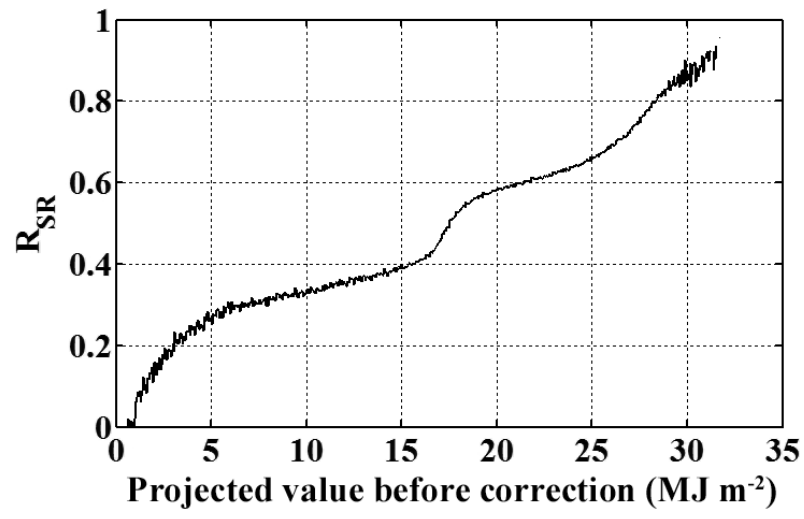

Fig. 8. Correction factor for daily solar radiation.
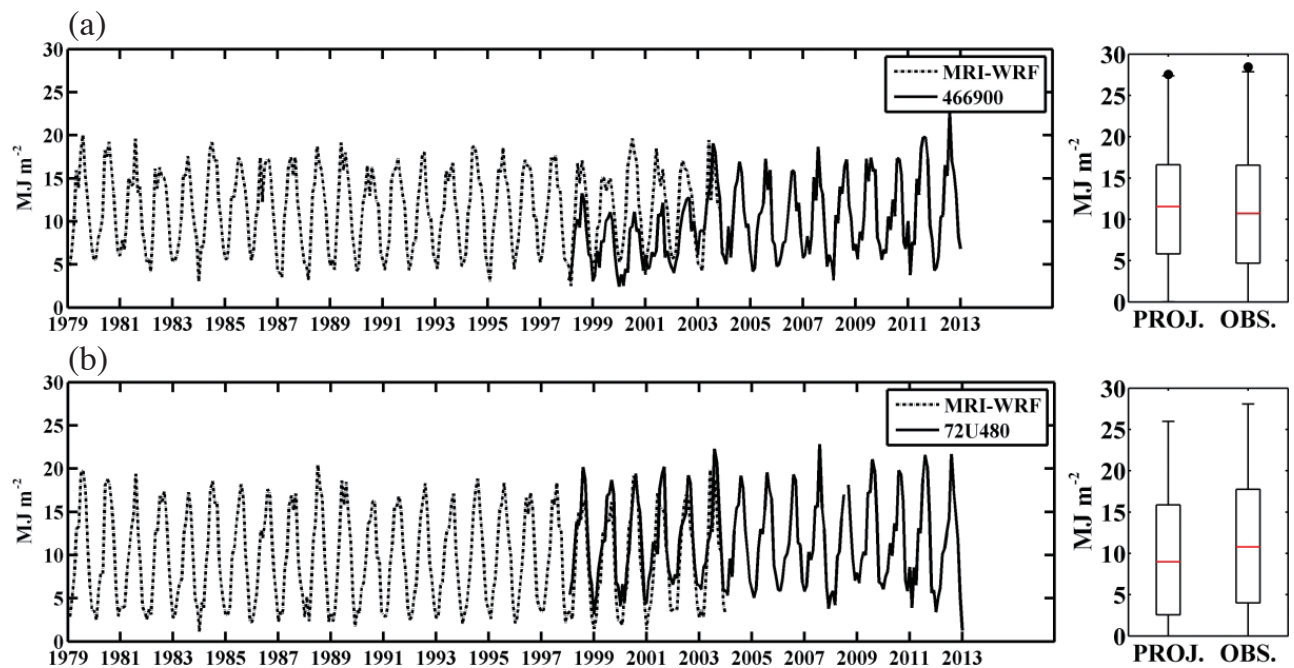

Fig. 9. After bias correction, comparison between monthly averaged solar radiation of MRI-WRF and observations and the boxplot of daily solar radiation of different gauges (a) CWB ID: 466900; (b) TARI ID: 72U480. 
were also much similar. From the scatter plots of averaged daily solar radiation (Fig. 10), the points are much closer to the equivalent line. The RMSE between the observed and projected average daily solar radiation also dropped from 7.90 to $1.82\left(\mathrm{MJ} \mathrm{m}^{-2}\right)$.

Figure 11a shows the average daily solar radiation from 33 gauges and a decreasing trend from southwest to northeast was observed. This trend was also maintained in the projected dataset. However, the original MRI-WRF output overestimation was obvious (Fig. 11b). After correction, the projected data spatial pattern did not change while the average daily solar radiation decreased to a level similar to that of the observed. The same correction factor applied to all 1566 projected grids and the average daily solar radiation are shown in Figs. 11d - f. The solar radiation in the southwest part of the area will decrease in the future. This was clear in the change rate maps for the early and late $21^{\text {st }}$ century. The solar radiation decrease could be up to $\sim 5 \%$ in the late $21^{\text {st }}$ century (Fig. 12). An interesting thing is that an increase in solar radiation of about $2 \%$ in the future was

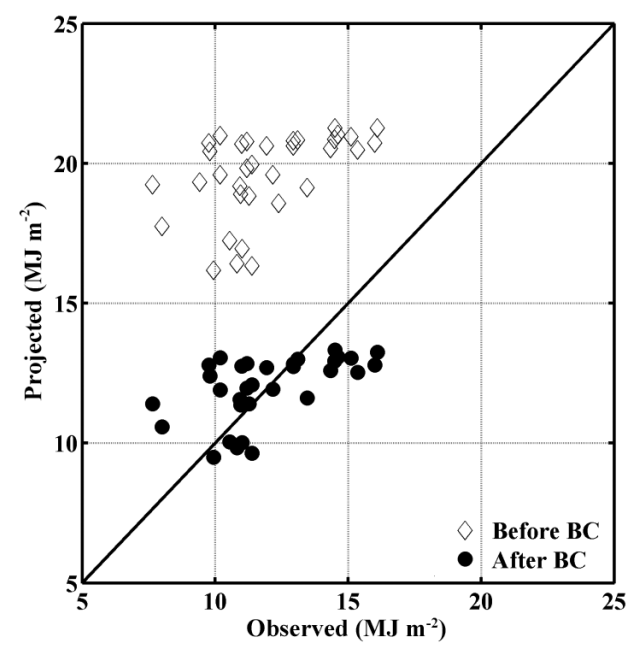

Fig. 10. Scatter plots of averaged daily solar radiation before and after bias correction.
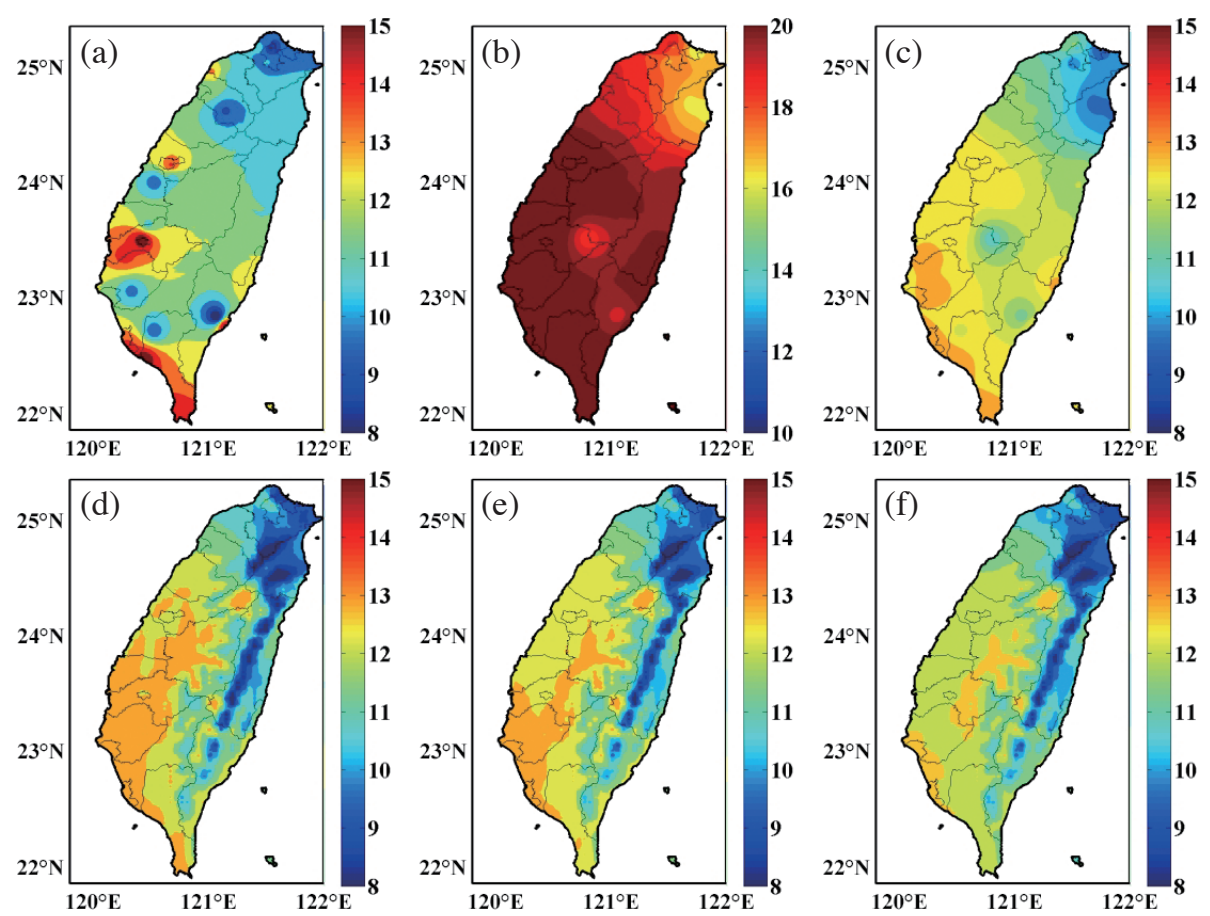

Fig. 11. Maps of average daily solar radiation (a) 84 gauges; and MRI-WRF (b) 84 grids before correction; (c) 84 grids in the baseline after correction; (d) all grids in the baseline after correction; (e) all grids in the early $21^{\text {st }}$ century after correction; (f) all grids in the late $21^{\text {st }}$ century after correction. Note that the (b) colour bar is different from the others. 


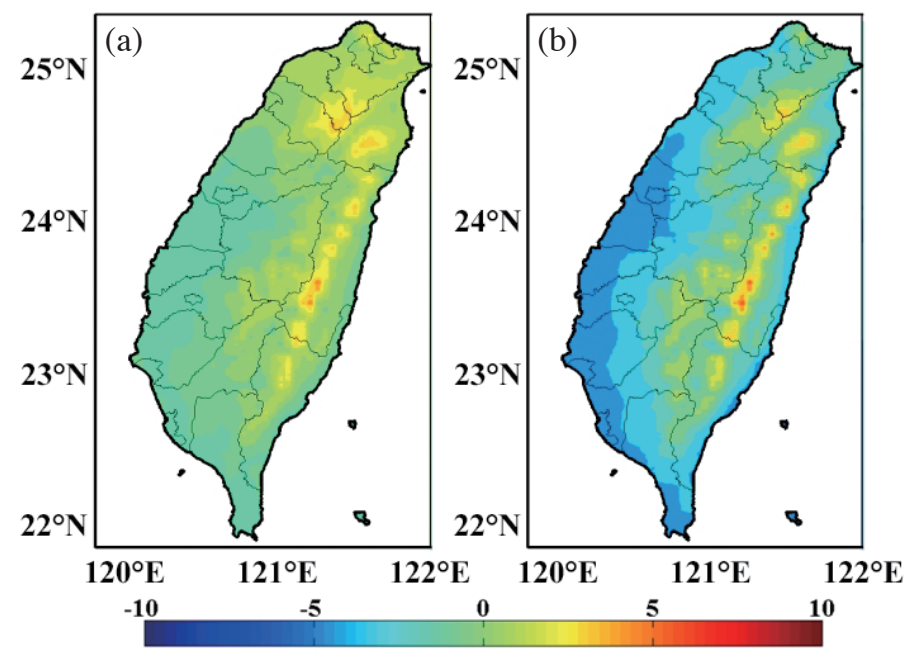

Fig. 12. Change rate $(\%)$ of future projection of solar radiation (a) the early $21^{\text {st }}$ century; (b) the late $21^{\text {st }}$ century.

observed in the northeast part of Taiwan, also corresponding to mountainous areas in Taiwan. The bias-corrected daily solar radiation, albeit not problem free, provided a reasonable representation of the solar radiation for the baseline and future projections and could be used for further agricultural applications under climate change scenarios.

\section{CONCLUSIONS}

Bias corrections using quantile mapping method to the MRI-WRF datasets, daily solar radiation and hourly typhoon rainfall, are presented in this study. The spatial patterns of possible future changes in solar radiation and typhoon rainfall are also explored. Our conclusions are discussed below:

(1) Quantile mapping applied to MRI-WRF datasets correct the original model outputs to have similar population characteristics as the observations and the correction factors for daily solar radiation and hourly typhoon rainfall were proposed. The biases in the original MRI-WRF model outputs, such as the daily solar radiation overestimation and hourly typhoon rainfall underestimation, were markedly reduced.

(2) The spatial patterns of future changes in solar radiation revealed a decreasing, up to $\sim 5 \%$ in the late $21^{\text {st }}$ century, in the south and west parts of Taiwan while an increase in solar radiation about $2 \%$ in the future was also observed in the mountain areas.

(3) Marked increases in typhoon rainfall, up to $\sim 50 \%$ in the late $21^{\text {st }}$ century and $20 \%$ in the early $21^{\text {st }}$ century, were observed in the west and central parts of Taiwan while a decrease, up to $\sim-30 \%$, was also clear in the north and east parts.

Acknowledgements The authors are grateful for the MRIAGCM3.2S dataset provided from Meteorological Research
Institute (MRI) through the cooperation between TCCIP projects (MOST 102-2621-M-492-001 and MOST 1032621-M-865-001) and SOUSEI project in Japan.

\section{REFERENCES}

Christensen, J. H., F. Boberg, O. B. Christensen, and P. Lucas-Picher, 2008: On the need for bias correction of regional climate change projections of temperature and precipitation. Geophys. Res. Lett., 35, L20709, doi: 10.1029/2008GL035694. [Link]

Elshamy, M. E., I. A. Seierstad, and A. Sorteberg, 2009: Impacts of climate change on Blue Nile flows using biascorrected GCM scenarios. Hydrol.Earth Syst. Sci., 13, 551-565, doi: 10.5194/hess-13-551-2009. [Link]

Haerter, J. O., S. Hagemann, C. Moseley, and C. Piani, 2011: Climate model bias correction and the role of timescales. Hydrol. Earth Syst. Sci., 15, 1065-1079, doi: 10.5194/hess-15-1065-2011. [Link]

Johnson, F. and A. Sharma, 2011: Accounting for interannual variability: A comparison of options for water resources climate change impact assessments. Water Resour.Res., 47, W04508, doi: 10.1029/2010WR009272. [Link]

Kitoh, A., A. Yatagai, and P. Alpert, 2008: First super-highresolution model projection that the ancient "Fertile Crescent" will disappear in this century. Hydrol. Res. Lett., 2, 1-4, doi: 10.3178/hrl.2.1. [Link]

Mao, G., S. Vogl, P. Laux, S. Wagner, and H. Kunstmann, 2015: Stochastic bias correction of dynamically downscaled precipitation fields for Germany through Copula-based integration of gridded observation data. Hydrol. Earth Syst. Sci., 19, 1787-1806, doi: 10.5194/ hess-19-1787-2015. [Link]

Mizuta, R., K. Oouchi, H. Yoshimura, A. Noda, K. Katayama, S. Yukimoto, M. Hosaka, S. Kusunoki, H. Kawai, 
and M. Nakagawa, 2006: 20-km-mesh global climate simulations using JMA-GSM model-Mean climate states. J. Meteorol. Soc. Jpn., 84, 165-185, doi: 10.2151/jmsj.84.165. [Link]

Mizuta, R., H. Yoshimura, H. Murakami, M. Matsueda, H. Endo, T. Ose, K. Kamiguchi, M. Hosaka, M. Sugi, S. Yukimoto, S. Kusunoki, and A. Kitoh, 2012: Climate simulations using MRI-AGCM3.2 with $20-\mathrm{km}$ grid. J. Meteorol. Soc. Jpn., 90A, 233-258, doi: 10.2151/ jmsj.2012-A12. [Link]

Oouchi, K., J. Yoshimura, H. Yoshimura, R. Mizuta, S. Kusunoki, and A. Noda, 2006: Tropical cyclone climatology in a global-warming climate as simulated in a $20 \mathrm{~km}$-mesh global atmospheric model: Frequency and wind intensity analyses. J.Meteorol.Soc. Jpn., 84, 259-276, doi: 10.2151/jmsj.84.259. [Link]
Rojas, R., L. Feyen, A. Dosio, and D. Bavera, 2011: Improving pan-European hydrological simulation of extreme events through statistical bias correction of RCM-driven climate simulations. Hydrol. Earth Syst. Sci., 15, 2599-2620, doi: 10.5194/hess-15-2599-2011. [Link]

Teutschbein, C. and J. Seibert, 2012: Bias correction of regional climate model simulations for hydrological climate-change impact studies: Review and evaluation of different methods. J. Hydrol., 456-457, 12-29, doi: 10.1016/j.jhydrol.2012.05.052. [Link]

Wood, A. W., L. R. Leung, V. Sridhar, and D. P. Lettenmaier, 2004: Hydrologic implications of dynamical and statistical approaches to downscaling climate model outputs. Clim. Change, 62, 189-216, doi: 10.1023/ B:CLIM.0000013685.99609.9e. [Link] 